University of Nebraska - Lincoln

DigitalCommons@University of Nebraska - Lincoln

Sociology Department, Faculty Publications

Sociology, Department of

$5-2004$

\title{
Risk Factors for Sexual Victimization Among Male and Female Homeless and Runaway Youth
}

\author{
Kimberly A. Tyler \\ University of Nebraska-Lincoln, kim@ktresearch.net \\ Les B. Whitbeck \\ University of Nebraska-Lincoln, Iwhitbeck2@unl.edu \\ Dan R. Hoyt \\ University of Nebraska-Lincoln, dhoyt2@unl.edu \\ Ana Mari Cauce \\ University of Washington
}

Follow this and additional works at: https://digitalcommons.unl.edu/sociologyfacpub

Part of the Sociology Commons

Tyler, Kimberly A.; Whitbeck, Les B.; Hoyt, Dan R.; and Cauce, Ana Mari, "Risk Factors for Sexual Victimization Among Male and Female Homeless and Runaway Youth" (2004). Sociology Department, Faculty Publications. 35.

https://digitalcommons.unl.edu/sociologyfacpub/35

This Article is brought to you for free and open access by the Sociology, Department of at DigitalCommons@University of Nebraska - Lincoln. It has been accepted for inclusion in Sociology Department, Faculty Publications by an authorized administrator of DigitalCommons@University of Nebraska - Lincoln. 
Published in Journal of Interpersonal Violence 19:5 (May 2004), pp. 503-520; doi 10.1177/0886260504262961 Copyright (C) 2004 Sage Publications; published on behalf of American Professional Society on the Abuse of Children. Used by permission. http://jiv.sagepub.com/cgi/content/abstract/19/5/503

The Seattle Homeless Adolescent Research and Education Project (SHARE) is supported by the National Institute on Alcohol Abuse \& Alcoholism (AA10253-05).

\title{
Risk Factors for Sexual Victimization Among Male and Female Homeless and Runaway Youth
}

\author{
Kimberly A. Tyler, ${ }^{1}$ Les B. Whitbeck, ${ }^{1}$ Dan R. Hoyt, ${ }^{1}$ \\ and Ana Mari Cauce ${ }^{2}$ \\ ${ }^{1}$ University of Nebraska-Lincoln \\ ${ }^{2}$ University of Washington \\ Corresponding author - Kimberly A. Tyler, University of Nebraska-Lincoln, \\ Department of Sociology, 717 Oldfather Hall, Lincoln, NE 68588-0324; \\ emailktyler2@unl.edu
}

\begin{abstract}
Risk factors associated with the likelihood of being sexually victimized by a stranger or friend/acquaintance since being on the street was examined among 372 homeless and runaway youth. Young people were interviewed on the streets and in shelters by outreach workers using a systematic sampling strategy. Youth who engaged in more high-risk behaviors were expected to be at greater risk for sexual victimization by both known and unknown assailants. Results indicated that for females, running from home for the first time at an earlier age was associated with sexual victimization by both a stranger and friend/acquaintance. However, engaging in deviant subsistence strategies, survival sex, and grooming predicted being sexually victimized by a friend/acquaintance. For males, survival sex and grooming predicted stranger sexual victimization, whereas sexual orientation was associated with sexual victimization by a friend/acquaintance. Overall, $35 \%$ of the sample had been sexually victimized.
\end{abstract}

Keywords: sexual victimization; perpetrators; homeless youth

Runaway and homeless youth experience high rates of victimization on the streets (Hoyt, Ryan, \& Cauce, 1999; Janus, McCormack, Burgess, \& Hartman, 1987). Even though risk factors such as participating in deviant subsistence strategies (e.g., robbing, conning), affiliating with deviant peers, and using alcohol or drugs are associated with sexual victimiza- 
tion while out on the street (Tyler, Hoyt, Whitbeck, \& Cauce, 2001; Whitbeck \& Hoyt, 1999), less is known about how specific risk factors impact males and females individually. In addition, little research to date has focused on the perpetrators of sexual victimization of homeless youth. As such, we know little about the young person's relationship to the perpetrator. Knowing the types of perpetrators and the risk factors associated with sexual victimization for males and females has important implications for providing intervention to these youth.

The purpose of the current study is twofold. First, this research looks individually at risk factors associated with sexual victimization for homeless males and females. Risk factors include the amount of time youth spend on the street, their participation in risky, deviant behaviors, and their personal characteristics. Second, this study tests the likelihood of males and females being sexually victimized by a known person (i.e., friend and/or acquaintance) versus an unknown person (i.e., stranger) since being on their own.

\section{Background}

Individuals with deviant lifestyles are at risk for becoming victims themselves because much of their contact takes place with other offenders (Baron, 1997; Hagan \& McCarthy, 1997; Lauritsen, Laub, \& Sampson, 1992). Lauritsen and colleagues (1992) pointed out that adolescent victims and offenders do not constitute mutually exclusive groups. The "principle of homogamy" (Sampson \& Lauritsen, 1990) holds that individuals who have characteristics similar to offenders are more likely to come into contact with these people and as a result, are more likely to be victimized. Because runaway and homeless youth frequently engage in delinquent activities, (Hagan \& McCarthy, 1997; Kipke, Montgomery, Simon, Unger, \& Johnson, 1997), they are likely to be at high risk for victimization.

Perpetrator research on the general population finds that female victims often know their assailant. In a community sample of women, Ullman and Siegel (1993) found that the majority of perpetrators were acquaintances. Similarly, Koss and colleagues' (1988) study of college women revealed that the overwhelming majority of sexual perpetrators were acquaintances. Acquaintances often include nonromantic relationships such as casual friends (Koss, Dinero, Seibel, \& Cox, 1988).

Although little research has addressed perpetrators of street youth, both strangers and friends/acquaintances are likely victimizers. It is possible that strangers pose more of a threat to homeless youth than to those in the general population because these youth spend so much of their time on the street, thereby increasing visibility. One study of home- 
less youth found that $60 \%$ of respondents reported being victimized by either a friend or an acquaintance, suggesting that many of the people with whom street youth affiliate are the same persons who are victimizing them (Baron, 1997). Other studies of similarly aged youth, albeit not specific to homeless populations, have also found the perpetrators to be peer groups, especially among adolescents with behavioral problems (Schwartz, McFadyen-Ketchum, Dodge, Pettit, \& Bates, 1999).

\section{Theoretical Framework}

Based on a sample of 372 homeless youth in Seattle, the current study uses victimization theories to individually examine the likelihood of males and the likelihood of females being sexually victimized by a stranger or friend/ acquaintance since being on their own. Victimization theories are useful for studying homeless and runaway youth because they take into account the social context of daily street life and the resources and survival needs that youth bring to this context. Specifically, lifestyle-exposure theory (Hindelang, Gottfredson, \& Garofalo, 1978) and routine-activity theory (Cohen \& Felson, 1979) argue that the lifestyles and daily routines of people's everyday lives are related to differential exposure to dangerous places and people, which creates the potential for crime opportunities and therefore for increased victimization. Homeless youth are expected to be particularly vulnerable to sexual victimization for several reasons. First, they spend a lot of time on the street, which makes them highly visible. Second, they engage in high-risk behaviors, which is likely to put them in close proximity to potential offenders. Third, those who are "offender" victims are less likely to go to the police (Sampson \& Lauritsen, 1990) because they may have had previous encounters with the law or they may believe that they or their complaints will not be taken seriously. If potential offenders think that they will not be reported by homeless youth, this makes these young people particularly vulnerable. Finally, certain characteristics of the youth, such as their physical appearance or sexual orientation, may put them at increased risk.

\section{Hypotheses}

Homeless adolescents who spend more time on the streets are at greater risk for victimization (Hoyt et al., 1999; Whitbeck \& Hoyt, 1999). Spending time on the street is associated with participation in dangerous activities (Janus et al., 1987; Kufeldt \& Nimmo, 1987), which increases the risk for victimization. Also, those who leave home for the first time at an early age may have fewer street survival skills and less experience, making them more susceptible to victimization. Being on the streets increases one's ac- 
cessibility to crime in addition to increasing the likelihood of contact between oneself and potential offenders (Miethe \& Meier, 1994). Moreover, because personal victimization is associated with the amount of time spent in public places, especially at night (Hindelang et al., 1978), runaways are at further risk because much of their time is spent on the streets. Therefore, it was expected that adolescents who leave home for the first time at an early age and those who run from home numerous times are highly "accessible" and at greater risk for sexual victimization by a stranger.

Many homeless adolescents engage in high-risk behaviors (Hagan \& McCarthy, 1997; Whitbeck \& Hoyt, 1999), which expose them to offenders, thus increasing their risk for victimization. Adolescents involved in deviant activities are at greater risk for assault compared to nondelinquents (Lauritsen, Sampson, \& Laub, 1991). Many studies have found that approximately $25 \%$ of homeless youth have engaged in survival sex, which is trading sex, often as a means of survival, for food, money, or a place to stay (Greene, Ennett, \& Ringwalt, 1999; Kipke et al., 1997; Kral, Molnar, Booth, \& Watters, 1997). Trading sex leads to high visibility and puts homeless youth in dangerous and vulnerable situations with little or no protection from violent customers and others who may try to exploit them. This may include either strangers and/or friends/acquaintances. Engaging in risky sexual behaviors is linked to victimization among homeless adolescents (Whitbeck \& Hoyt, 1999).

Substance abuse has been linked to an increased risk for victimization among homeless adolescents (Hoyt et al., 1999). In one study of homeless youth, $75 \%$ of respondents reported being under the influence of alcohol or drugs while engaging in sex (Kral et al., 1997). Street youth also have high rates of alcohol and drug use and indicate hanging out with peers who report weekly use (Kipke et al., 1997; Koopman, Rosario, \& Rotheram-Borus, 1994). Studies of college women have found that almost half of the victims had been drinking before being sexually assaulted. Women who had been raped by a stranger were more likely to report having used drugs and/ or alcohol compared to women who were raped by an acquaintance (Koss et al., 1988). Individuals who are intoxicated may appear more vulnerable and also may take fewer precautions to avoid victimization (cf. Felson, 1997). Being intoxicated around friends and/or in the presence of strangers may increase their chances for sexual victimization.

Based on the above findings, it was hypothesized that homeless youth who engage in deviant subsistence strategies, associate with deviant peers, have high rates of drug use, and engage in survival sex are more likely to be sexually victimized by both friends/acquaintances and strangers. 
Youth with well-kept physical appearances may be more likely to be chosen as potential victims independent of anything they do because their attractive appearance may be a characteristic that is congruent with the needs and motives of the sexual offender (Finkelhor \& Asdigian, 1996). Following this, it was expected that those with well-kept physical appearances would be more likely to be at risk for sexual victimization by a friend/acquaintance or stranger.

Homeless gay, lesbian, and/or bisexual (GLB) youth are often isolated from friends and family members. Many have experienced physical and/ or sexual abuse perpetrated by family and/or peers, and many are asked to leave home when their sexual orientation is revealed (Savin-Williams, 1994). Once on the streets, they, like other homeless youth, are at risk due to their participation in high-risk behaviors but may be at additional risk due to their sexual orientation. GLB youth also engage more frequently in survival sex compared to other homeless youth (cf. Kipke et al., 1997; Pennbridge, Freese, \& MacKenzie, 1992), and participating in survival sex is linked to sexual victimization (Whitbeck \& Hoyt, 1999). Kipke and colleagues (1997) found that homeless GLB youth were 3 times as likely to have engaged in survival sex (Kipke et al., 1997). In terms of gender, Kruks (1991) found that $72 \%$ of homeless male youth who reported engaging in survival sex were gay or bisexual, whereas among homeless female youth, only $8 \%$ involved in survival sex were gay or bisexual. Based on these findings, it was hypothesized that GLB youth would be more likely to be sexually victimized by both strangers and friends/acquaintances compared to non-GLB youth.

\section{Method}

\section{Procedure}

It is well established that it is not possible to randomly sample homeless populations (Wright, Allen, \& Devine, 1995) because unbiased enumeration is not realistic. Therefore, young people were interviewed using a systematic sampling strategy that maximized locating homeless and runaway youth in metropolitan Seattle. This strategy employed both street intercepts and locale interviewing. The locales, which provided homeless youth with services, were contacted to obtain permission to give interviewers access to youth. Interviewers work through the local service agencies to create greater access to youth and minimize the impression of an intrusive researcher in that they collect data and serve as a referral source for those services that may be requested by young people in crisis. Young people were interviewed over a period of 2 years (Febru- 
ary 1996 to February 1998) by outreach workers who were trained youth workers with considerable experience interviewing and interacting with this group of young people. Many had served as interviewers on a prior study of homeless and runaway youth, and they were very knowledgeable with areas of the city where youth could be located and had prior experience working with young people in these settings. Furthermore, interviewers were very familiar with local street cultures and were already known and trusted by many of the runaways.

Interviewers approached all available youth who passed through or were at the locale and appeared to be between the ages of 13 and 21. In the state of Washington, adolescents can be considered emancipated at the age of 13 (described below). Street intercepts were made by approaching youth in the areas of the city frequented by homeless and runaway adolescents. These street intercept interviews were conducted at numerous locations such as coffee houses and restaurants. In addition to solicitations by the interviewers, youth also were recruited through flyers posted in the local agencies and group informational meetings held at the agencies.

Youth were first administered a brief "eligibility" interview. If deemed to be eligible, the study and procedures were explained and informed consent was obtained from interested youth. Eligible youth were between 13 and 21 years of age, spoke English, and did not, at the time of the interview, have a stable residence, have a viable home to which they could return, and were not physically in the custody of the state. Youth staying at foster care or temporarily housed with family were also eligible. If the youth had been on the streets less than 1 week, parental permission was obtained prior to the interview. This was done by obtaining parental contact information from the youth, and then parents/guardians were telephoned by project staff who explained the study to them and obtained modified informed consent. In the state of Washington, adolescents can be considered emancipated at the age of 13 . In addition to meeting this age criterion, however, youth were considered emancipated only if they were judged as having no significant contact with parents, including no longer being financially dependent on them, and if they did not spend any time at home for a week prior to the interview. If the youth met all these criteria, they were considered emancipated and were allowed to provide sole consent.

Respondents were informed that they could refuse participation, refuse single questions, or stop participating in the interview at any time. If young people agreed to participate and complete consent forms, interviewers took the youth to a quiet, private location to conduct the interview. Due to the length of the questionnaire, the interview was conducted in two parts on separate days. Each section took approximately 
1.5 to 2 hours to complete. The youth were paid $\$ 10$ for each section, with a $\$ 5$ bonus for completing both sections. Thus, they were offered $\$ 25$ for the entire completed interview. The Institutional Review Board at the University of Washington approved this study.

\section{Measures}

Age at first run was a single item that asked adolescents how old they were when they left home for the first time (Mean $=13.3$ years).

Number of times run was a single-item measure that asked respondents the total number of times that they had ever run away from home (Mean $=9.5$ runs).

Hard drug use was measured using 11 items in which respondents were asked about frequency of use of drugs such as cocaine/crack, acid, mushrooms, ecstasy, and heroin/opium during the past 6 months. Due to skewness, each of the 11 items were dichotomized $(0=$ no use, $1=$ used the substance at least once) and then summed. The composite measure for hard drugs ranged from 0 to 11, with a mean of 3.2. Cronbach's alpha for the 11 dichotomized items was .83 .

Deviant subsistence strategies was measured using 6 items that focused on different tactics adolescents may have used since being on the street (e.g., shoplifting, conning, mugging) to survive. Due to skewness of the individual items, each indicator was dichotomized $(0=$ never and $1=$ at least once) and then a count was done to form a scale of deviant subsistence strategies. Deviant peers was measured using 13 items in which young people were asked, for example, if any of their close friends had ever sold drugs, used drugs, sold sexual favors, or threatened and/or assaulted someone with a weapon $(0=$ no; $1=$ yes $)$. The 13 items were summed and the composite scale ranged from 0 to 13. Cronbach's alpha is .87 .

Survival sex was a single item that asked respondents how often they had traded sex since being on their own. Due to skewness, the item was dichotomized $(0=$ never traded sex, $1=$ traded sex at least once $)$.

Grooming was a two-item indicator, which the interviewers responded to regarding the appearance of the youth. The two items included: "What was your impression of this youth's physical appearance: facial and body features?" and "What was your impression of this youth's physical appearance: grooming, dress, and cleanliness?" Possible responses for these two items ranged from 1 (very unattractive) to 5 (very attractive). The two grooming items were summed such that the higher the score, the more well-kept or pleasing the physical appearance. The bivariate correlation between these two items was .47 . 
Sexual orientation was dichotomized into two groups $(0=$ heterosexual; 1 = gay, lesbian, bisexual).

The dependent variable was created by combining two variables: sexual victimization and relationship to perpetrator. The sexual victimization variable consisted of six items that focused on whether respondents had any unwanted or unpleasant sexual experiences with people since they had been on their own. For example: "Has anyone forced you to do something sexual?" and "Has anyone had you touch them sexually when you didn't want to?" (see appendix for all the questions). Cronbach's alpha for the six sexual victimization items was .81. Due to skewness, a dichotomous measure of sexual victimization was created $(0=$ never been sexually victimized and $1=$ have been sexually victimized at least once). The "relationship to perpetrator" question asked adolescents who were sexually victimized, "Since you've been on your own, who was the person who most often did these things to you?" Response categories included: 1 = friend, 2 = someone you know (acquaintance), and 3 $=$ stranger. To test specific hypotheses, three categories were created for the dependent variable by combining the sexual victimization variable and the perpetrator variable. The first category was computed by selecting those who had been sexually victimized and when the perpetrator was a stranger (category 3 above). The second category of the dependent variable was computed by selecting those who had been sexually victimized and when the perpetrator was a friend/acquaintance (categories 1 and 2 from above were combined). Friends and acquaintances were grouped into one category because we were interested in whether young people were being victimized by someone they know or someone they have had no previous interactions with (i.e., stranger). The final category of the dependent variable consisted of those adolescents who had not been sexually victimized, and they are used as the reference category in the model.

\section{Data Analysis}

Multinomial logistic regression (MLR) in SPSS (Version 10.1) was used to run two separate models, one for males and one for females, to examine risk factors associated with the likelihood of being sexually victimized by a stranger or friend/acquaintance since being on their own. MLR is an extension of standard logistic regression analysis to include more than two categories in the dependent variable. One group is selected as the reference group, and each of the remaining groups is compared to the reference group in separate logistic regression models that are estimated simultaneously (DeMaris, 1992). In the present study, the baseline group 
consists of youth who were not sexually victimized, and the other two groups consist of youth who were sexually victimized by (a) a stranger or (b) a friend/acquaintance. Although homeless females are victimized sexually at a higher rate compared to homeless males (Cauce et al., 2000; Weisberg, 1985), little is known about the importance of risk factors associated with sexual victimization for each sex in relation to different perpetrators; therefore, separate models are run for males and females. The purpose is not to compare males and females across models but rather to look at these two groups individually to assess risk. Both models controlled for the effects of age.

\section{Results}

\section{Participants}

A total of 372 adolescents were interviewed. Just more than half of the sample was male $(n=203 ; 54.6 \%)$. Ages ranged from 13 to 21 , with a median of 17 years. In terms of race, $48 \%$ were White, $6 \%$ were African American, 5\% were Native American, 3\% were Hispanic, and 2\% were Asian. Thirty- six percent of the sample was biracial or multiracial. A total of 81 youth (22\%) identified as GLB. Eleven percent of youth reported trading sex at least once ( $9 \%$ and $13 \%$ for males and females, respectively). In terms of sexual victimization, $14 \%$ indicated that the perpetrator was a stranger and $21 \%$ reported that the perpetrator was a friend/ acquaintance. Sixty-five percent of these young people had not experienced sexual victimization since being on the street. Of the approximate 392 youth who were approached for an interview, 372 met eligibility requirements and were interviewed, resulting in an overall response rate of $95 \%$. Young people may have been ineligible due to their age, not meeting our definition of homeless, or being incapable of doing an interview (e.g., being "high") at the time.

\section{Females}

Of the total sample, $23 \%$ of females have experienced sexual victimization on at least one occasion since being on the street. Table 1 (columns 1 and 2) revealed that for those young women who were sexually victimized, the perpetrator reported most often was a male acquaintance $(41 \%)$. The second most frequent perpetrator was a male stranger (34\%), followed by a male friend (23\%). Clearly, the overwhelming majority of perpetrators $(98 \%)$ of female sexual victimization were men. 
Table 1: Perpetrators Who Sexually Victimized Female Youth and Male Youth (by Perpetrator Gender)

\begin{tabular}{lrrrr}
\hline & \multicolumn{2}{c}{$\begin{array}{c}\text { Female }(N=83) \\
\text { Number }\end{array}$} & \multicolumn{2}{c}{$\begin{array}{c}\text { Male }(N=41) \\
\text { Number }\end{array}$} \\
\hline Stranger & & & & \\
$\quad$ Male & 28 & 33.7 & 21 & 51.2 \\
Female & 0 & - & 2 & 4.9 \\
$\quad$ Total & 28 & 33.7 & 23 & 56.1 \\
Friend & & & & \\
$\quad$ Male & 19 & 22.9 & 2 & 4.9 \\
Female & 2 & 2.4 & 3 & 7.3 \\
$\quad$ Total & 21 & 25.3 & 5 & 12.2 \\
Acquaintance & & & & \\
$\quad$ Male & 34 & 41.0 & 6 & 14.6 \\
Female & 0 & - & 7 & 17.1 \\
$\quad$ Total & 34 & 41.0 & 13 & 31.7 \\
& & & & \\
\hline
\end{tabular}

Males

A total of $11 \%$ of males reported being sexually victimized on at least one occasion since being on the street. Table 1 (columns 3 and 4) revealed that strangers were listed most frequently (56\%). Acquaintances were reported as the second most common perpetrator (32\%), followed by friends (12\%). Interestingly, $29 \%$ of all sexual perpetrators of young men were female. However, the majority of sexual victimizers of homeless males were still men.

\section{Multivariate Results}

Separate MLR models were estimated for females and males, but both are presented in Table 2. Collinearity did not appear to be a problem in any of the models because variance inflation factors (VIFS) were all well below 10 (Kleinbaum, Kupper, Muller, \& Nizam, 1998).

\section{Females}

The results for females are reported in the first two columns of Table 2. Predictors of stranger sexual victimization revealed that age was significant $(\operatorname{Exp} .[B]=1.72)$. That is, for each year increase of age, the odds of females being sexually victimized by a stranger increased $72 \%$. The earlier that young women ran away from home, the more likely they were 
to have been sexually victimized by a stranger $(\operatorname{Exp} .[B]=0.78)$. That is, when running away 1 year earlier, the odds were $22 \%$ higher of being sexually victimized by a stranger. Finally, females who reported higher rates of hard drug use were also more likely to have been sexually victimized by a stranger $(\operatorname{Exp} .[B]=1.28)$. That is, for each unit increase in different type of drug used, the odds of females being sexually victimized by a stranger increased $28 \%$.

Predictors of friend/acquaintance sexual victimization of females (see Table 2, column 2) revealed once again that age and age at first run were significant. Deviant subsistence strategies, survival sex, and grooming were all significantly associated with friend/acquaintance sexual victimization $(p<.05)$ based on a one-tailed test in the hypothesized direction. Females who trade sex were almost 5 times more likely to have been sexually victimized by a known assailant $(\operatorname{Exp} .[B]=4.81)$. For each unit increase in deviant subsistence strategies, the odds of being sexually victimized by a friend/acquaintance were $40 \%$ higher $(\operatorname{Exp} .[B]=1.40)$, as were those with a well-kept physical appearance (Exp. $[B]=1.39)$.

\section{Males}

The results for males (see Table 2, columns 3 and 4) revealed that survival sex and grooming were both positively associated with stranger sexual victimization. Males who sold sex were more than 6 times as likely to have been sexually victimized by a stranger $(\operatorname{Exp} .[B]=6.32)$. Also, young men with well-kept physical appearances were more than 1.5 times as likely to have been victimized by an unknown assailant (Exp. $[B]=1.65)$. Or put another way, for each unit increase in grooming, the odds of males being sexually victimized by a stranger increased $65 \%$.

The results for friend/acquaintance sexual victimization indicated that sexual orientation was the strongest predictor. Young men who self-identified as gay or bisexual were more than 5 times as likely to have been sexually victimized by a friend/acquaintance $(\operatorname{Exp} .[B]=5.77)$. Based on a one-tailed test in the hypothesized direction, the more times males ran away from home, the more likely they were to have been sexually victimized by a known assailant $(\operatorname{Exp} .[B]=1.03)$.

\section{Discussion}

Consistent with previous research (Hoyt et al., 1999; Janus et al., 1987; Weisberg, 1985), the current study found that both males and females experienced sexual victimization since being on the street but that the percentage for females was twice that of males (23\% versus $11 \%)$. For both 


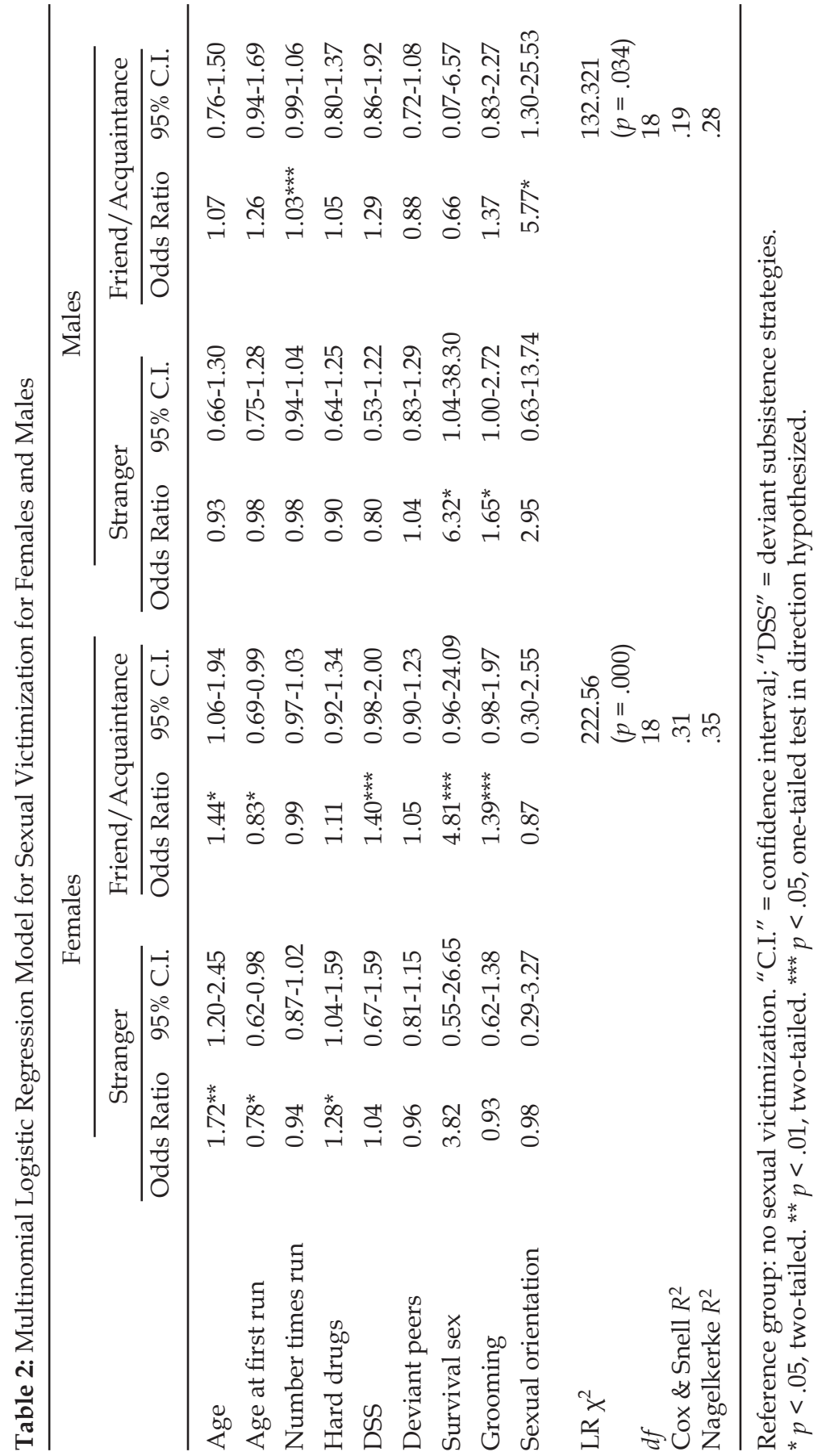


victimizers of males and females, the majority of perpetrators were men. However, $29 \%$ of individuals who sexually victimized the young men were female. The most likely victimizer for girls was a male acquaintance; for boys, it was a male stranger.

The current study makes several important contributions to the paucity of literature on perpetrators of homeless youth. First, we found that the perpetrator who most often sexually victimized these young people differed for males and females. Second, youth who traded sex were likely to be sexually victimized by different types of assailants; for females, the perpetrator was more likely to be a known assailant, whereas for males, the perpetrator was unknown. Third, having a well-kept physical appearance was associated with sexual victimization. Fourth, we found sexual orientation to be a strong predictor of being sexually victimized by a known assailant for the young men in this study. Finally, different characteristics and behaviors differentially impact sexual victimization for homeless males and females.

Although a number of hypotheses were not supported, the discussion that follows mainly focuses on significant findings. Multivariate analyses revealed that for females, running from home at an earlier age was related to stranger sexual victimization. It is possible that young women without a stable residence to which they can return are likely to spend more time out on their own. Being on the street makes them highly visible to potential offenders, thus increasing their risk for sexual victimization. Older females were also more likely to have reported stranger sexual victimization. One possible explanation is that older females are likely to spend more time out on the street rather than in shelters and this again increases their visibility, thereby making them more vulnerable. Consistent with the literature (Hoyt et al., 1999; Janus et al., 1987), spending time on the street is associated with an increased risk for sexual victimization by a stranger.

Female youth who reported higher rates of hard drug use were also likely to be sexually victimized by a stranger. One explanation is that being high on drugs is likely to limit young women's capacity to protect themselves. It is also possible that potential offenders see homeless females as vulnerable when they are high on drugs and therefore they are an easy target for sexual victimization. Consistent with the work of others (Hoyt et al., 1999), a positive link exists between substance use and an increased risk for sexual victimization among homeless adolescents. This finding is also congruent with studies of college women that find a positive association between stranger rape and drug use (Koss et al., 1988).

In addition to age and age at first run being associated with friend/ acquaintance sexual victimization, deviant subsistence strategies was 
also significant. Homeless youth often have deviant lifestyles, which are linked with becoming a victim because much of their contact takes place with other offenders. In addition, because youth typically engage in deviant behaviors with their friends, this is likely to increase young women's chances for sexual victimization by friends or acquaintances, a finding that is consistent with other studies (Baron, 1997; Hagan \& McCarthy, 1997; Whitbeck \& Hoyt, 1999).

Females who traded sex reported being sexually victimized by a known assailant. Many homeless youth trade sex, often as a means of survival, for food, money, or a place to stay (Greene et al., 1999; Kipke et al., 1997; Kral et al., 1997). It is likely that these young homeless women have very few resources and limited options. Even though they may not be on the streets prostituting for money, many of them may be coerced by friends and/or acquaintances into trading sex for food or a place to stay. This may explain why survival sex was associated with friend/acquaintance sexual victimization but not stranger sexual victimization. Grooming was also positively associated with friend/acquaintance sexual victimization, indicating that young women who have a well-kept and attractive physical appearance were more likely to be victims. However, grooming was not associated with stranger sexual victimization. It is possible that unknown assailants do not view well-groomed young women as homeless; therefore, they are less likely to be preyed on.

Young men who traded sex were more than 6 times as likely to be sexually victimized by strangers. For survival purposes, many male youth turn to trading sex, which puts them in a vulnerable position. Being out on the street and recruiting potential customers makes them highly visible targets, easily accessible by potential offenders. However, trading sex only predicted stranger sexual victimization but not friend/acquaintance sexual victimization. One possible explanation is that these young men are going outside their circle of friends to obtain what they need. Instead of relying on people they know for food, shelter, and the like, they may be turning to the street and relying on trading sex with strangers for money.

Well-groomed males were also likely to be sexually victimized by strangers. If they are trading sex with strangers or prostituting themselves, their appearance may be important to their customers who, in some cases, may be the sexual offenders. Consistent with Finkelhor and Asdigian (1996), an attractive and well-kept physical appearance is a characteristic congruent with the needs of the sexual perpetrator.

Gay and/or bisexual males were almost 6 times more likely to have been sexually victimized by a friend or acquaintance. Many gay and bisexual youth experience unique stressors in their lives linked to their sex- 
ual identity and often suffer ridicule and assault perpetrated by their peers (Savin- Williams, 1994). This would explain why gay and/or bisexual males are likely to experience sexual victimization at the hands of both male and female friends/acquaintances. Finally, many homeless gay and/or bisexual male youth report trading sex (Kruks, 1991), and this activity increases the risk for sexual victimization.

The current findings can be explained by victimization theories. Due to limited resources and the need to survive, homeless youth often engage in lifestyles and daily routines that expose them to dangerous places and people. In addition to their daily routines, spending time on the street also exposes them to potential offenders, thus increasing the risk for sexual victimization. Finally, certain personal characteristics of these young people are also associated with the risk for sexual victimization by strangers and/or friends/ acquaintances.

Some limitations should be kept in mind when interpreting these results. First, results are based on youth self-reports. Second, some of the measures are retrospective (e.g., age at first run), which may have resulted in some over-or underreporting. In addition, the frequencies generated on the perpetrators should be viewed as a low estimate as respondents were only reporting on the person who "most often" sexually victimized them rather than indicating multiple types of perpetrators. Finally, specific details of victimization incidence are limited.

Future research should focus on the relationships that these young people have with other street youth. The fact that many sexual perpetrators are friends indicates the lack of support and trust that is characteristic of these young people's lives. Knowing more about the specific details of their relationships (e.g., Are females trading sex with friends out of necessity for food or a place to stay? Are the friends who have sexually victimized them the same people that they hang out with? Do they continue interacting with these people after being sexually victimized?) would be helpful for explaining why victimization is occurring.

These results have practical implications for those who work with homeless and runaway youth. Engaging in high-risk behaviors such as drug use, survival sex, and deviant subsistence strategies increases risk for victimization. Early intervention for youth who are new to the streets, through increased funding for safe-houses, drop-in centers, and especially for street- based outreach workers, is needed for young people. Being able to reach these young people and to let them know about potential opportunities, such as assistance with completing their high school education and job training, may save some of them from having to resort to trading sex. Increased job opportunities would facilitate getting them 
off the streets and directly and/or indirectly lower their risk for sexual victimization. That is, if these youth had a stable residence, then daily survival needs (i.e., finding food and shelter) would not be their first concern and they would be less likely to trade sex and to hang out on the streets, which increases their exposure and their risk for victimization. Many of these young people have limited resources, and unless we work toward getting them off the streets, they will continue to be exposed to a dangerous environment and as a result, will continue to be at risk for victimization.

In summary, males and females experience different risks out on the street. For females, age, high usage of hard drugs, and age at first run predicted stranger victimization, whereas deviant subsistence strategies, survival sex, grooming, age, and age at first run predicted sexual victimization by a friend/acquaintance. Among males, trading sex and physical appearance were associated with stranger victimization, but sexual orientation predicted victimization by a friend/acquaintance. It is important to examine males and females separately because different risks may require unique solutions.

\section{Appendix}

Sexual Victimization Since Being on the Street Questions

Since being on your own, how often has someone ever ...

1. Forced you to do something sexual or messed around with you sexually when you didn't want to.

2. Had you touch them sexually when you didn't want to.

3. Kissed or touched you sexually, like on your butt, breast, or genitals ("private parts") when you didn't want them to.

4. Put or tried to put anything or any part of their body into you sexually (like into your vagina, butt, or mouth) when you didn't want them to.

5. Made you watch them do something sexual when you didn't want to (e.g., masturbate).

6. Made you show your "private parts" in person or for a camera when you didn't want to.

\section{References}

Baron, S. W. (1997). Risky lifestyles and the link between offending and victimization. Studies on Crime and Crime Prevention, 6, 53-71.

Cauce, A. M., Paradise, M., Embry, L., Ginzler, J. A., Morgan, C., Lohr, Y., et al. (2000). The characteristics and mental health of homeless adolescents: Age and gender differences. Journal of Emotional and Behavioral Disorders, 8, 230-239. 
Cohen, L. E., \& Felson, M. (1979). Social change and crime rate trends: A routine activity approach. American Sociological Review, 44, 588-608.

DeMaris, A. (1992). Logit modeling: Practical applications (Sage Quantitative Applications in the Social Sciences Series 07-086). Newbury Park, CA: Sage.

Felson, R. B. (1997). Routine activities and involvement in violence as actor, witness or target. Violence and Victims, 12, 209-221.

Finkelhor, D., \& Asdigian, N. L. (1996). Risk factors for youth victimization: Beyond a lifestyle/ routine activities theory approach. Violence and Victims, 11, 3-19.

Greene, J. M., Ennett, S. T., \& Ringwalt, C. L. (1999). Prevalence and correlates of survival sex among runaway and homeless youth. American Journal of Public Health, 89, 1406-1409.

Hagan, J., \& McCarthy, B. (1997). Mean streets: Youth crime and homelessness. New York: Cambridge University Press.

Hindelang, M. J., Gottfredson, M. R., \& Garofalo, J. (1978). Victims of personal crime: An empirical foundation for a theory of personal victimization. Cambridge, MA: Ballinger.

Hoyt, D. R., Ryan, K. D., \& Cauce, A. M. (1999). Personal victimization in a high-risk environment: Evaluating the relative effects of exposure, attractiveness and guardianship. Journal of Research in Crime and Delinquency, 36, 371-392.

Janus, M., McCormack, A., Burgess, A. W., \& Hartman, C. (1987). Adolescent runaways: Causes and consequences. Lexington, MA: Lexington Books.

Kipke, M. D., Montgomery, S. B., Simon, T. R., Unger, J. B., \& Johnson, C. J. (1997). Homeless youth: Drug use patterns and HIV risk profiles according to peer group affiliation. AIDS and Behavior, 1, 247-259.

Kleinbaum, D. G., Kupper, L. L., Muller, K. E., \& Nizam, A. (1998). Applied regression analysis and other multivariable methods. Pacific Grove, CA: Brooks/Cole.

Koopman, C., Rosario, M., \& Rotheram-Borus, M. J. (1994). Alcohol and drug use and sexual behaviors placing runaways at risk for HIV infection. Addictive Behaviors, 19, 95-103.

Koss, M. P., Dinero, T. E., Seibel, C. A., \& Cox, S. L. (1988). Stranger and acquaintance rape: Are there differences in the victim's experience? Psychology of Women Quarterly, 12, $1-24$.

Kral, A. H., Molnar, B. E., Booth, R. E., \& Watters, J. K. (1997). Prevalence of sexual risk behavior and substance use among runaway and homeless adolescents in San Francisco, Denver and New York City. International Journal of STD \& AIDS, 8, 109-117.

Kruks, G. (1991). Gay and lesbian homeless/street youth: Special issues and concerns. Journal of Adolescent Health, 12, 515-518.

Kufeldt, K., \& Nimmo, M. (1987). Youth on the street: Abuse and neglect in the eighties. Child Abuse \& Neglect, 11, 531-543.

Lauritsen, J. L., Laub, J. H., \& Sampson, R. J. (1992). Conventional and delinquent activities: Implications for the prevention of violent victimization among adolescents. Violence and Victims, 7, 91-108.

Lauritsen, J. L., Sampson, R. J., \& Laub, J. H. (1991). The link between offending and victimization among adolescents. Criminology, 29, 265-291.

Miethe, T. D., \& Meier, R. F. (1994). Crime and its social context: Toward an integrated theory of offenders, victims, and situations. Albany, NY: State University of New York Press.

Pennbridge, J. N., Freese, T. E., \& MacKenzie, R. G. (1992, Fall). High-risk behaviors among male street youth in Hollywood, California. AIDS Education and Prevention (Supp.), pp. 24-33. 
Sampson, R. J., \& Lauritsen, J. L. (1990). Deviant lifestyles, proximity to crime, and the offender-victim link in personal violence. Journal of Research in Crime and Delinquency, 27, 110-139.

Savin-Williams, R. C. (1994). Verbal and physical abuse as stressors in the lives of lesbian, gay male, and bisexual youths: Associations with school problems, running away, substance abuse, prostitution, and suicide. Journal of Consulting and Clinical Psychology, $62,261-269$.

Schwartz, D., McFadyen-Ketchum, S., Dodge, K. A., Pettit, G. S., \& Bates, J. E. (1999). Early behavior problems as a predictor of later peer group victimization: Moderators and mediators in the pathways of social risk. Journal of Abnormal Child Psychology, 27, 191-201.

Tyler, K. A., Hoyt, D. R., Whitbeck, L. B., \& Cauce, A. M. (2001). The impact of childhood sexual abuse on later sexual victimization among runaway youth. Journal of Research on Adolescence, 11, 151-176.

Ullman, S. E., \& Siegel, J. M. (1993). Victim-offender relationship and sexual assault. Violence \& Victims, 8, 121-133.

Weisberg, D. K. (1985). Children of the night: A study of adolescent prostitution. Lexington, MA: Lexington Books.

Whitbeck, L. B., \& Hoyt, D. R. (1999). Nowhere to grow: Homeless and runaway adolescents and their families. New York: Aldine.

Wright, J. D., Allen, T. L., \& Devine, J. A. (1995). Tracking non-traditional populations in longitudinal studies. Evaluation and Program Planning, 18, 267-277.

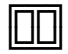

Kimberly A. Tyler is an assistant professor in sociology at the University of Nebraska-Lincoln. Her research interests include child abuse and neglect, victimization, mental disorders, foster care youth, and homeless youth and their families.

Les B. Whitbeck is professor of sociology at the University of Nebraska-Lincoln. His research focuses on runaway and homeless adolescents and other high-risk adolescent behaviors.

Dan R. Hoyt is professor of sociology and director of the Bureau of Sociological Research at the University of Nebraska-Lincoln. His current research interests include the mental health impacts of early life trauma, substance abuse, and adolescent victimization.

Ana Mari Cauce is professor of psychology and American ethnic studies at the University of Washington. Her research interests include at-risk youth and normative and nonnormative development in ethnic minority adolescents. 